\title{
Vitamin D Deficiency Is Associated with Pulmonary Exacerbations in Children with Cystic Fibrosis
}

\author{
Laura A. McCauley ${ }^{1}$, William Thomas ${ }^{2}$, Theresa A. Laguna ${ }^{3}$, Warren E. Regelmann ${ }^{3}$, Antoinette Moran ${ }^{3}$, \\ and Lynda E. Polgreen ${ }^{3}$ \\ ${ }^{1}$ Department of Pediatrics, Marshfield Clinic, Marshfield, Wisconsin; and ${ }^{2}$ Department of Biostatistics, and ${ }^{3}$ Department of Pediatrics, \\ University of Minnesota, Minneapolis, Minnesota
}

\begin{abstract}
Rationale: Recent literature suggests vitamin D has an effect on lung function and on the lung's ability to fight infection, both important in the cystic fibrosis (CF) population as predictors of morbidity and mortality.
\end{abstract}

Objectives: Our study assessed associations between vitamin D and $\%$ predicted lung function, pulmonary exacerbations, and first Pseudomonas aeruginosa infection in children with CF. We hypothesized that children with CF who have 25-hydroxy vitamin D (25-OHD) levels less than $30 \mu \mathrm{g} / \mathrm{L}$ would have lower $\%$ predicted lung function and more pulmonary exacerbations than those with $25-\mathrm{OHD}$ greater than or equal to $30 \mu \mathrm{g} / \mathrm{L}$.

Methods: This retrospective longitudinal study of 130 children aged 6 to 18 years between 2000 and 2012 examined 25-OHD levels classed in three vitamin D groups: sufficient $(\geqslant 30 \mu \mathrm{g} / \mathrm{L})$, insufficient $(20-29 \mu \mathrm{g} / \mathrm{L})$, and deficient $(<20 \mu \mathrm{g} / \mathrm{L})$. Longitudinal models followed individuals' changing vitamin $\mathrm{D}$ groups over time to compare numbers of pulmonary exacerbations (defined by hospitalization), incidence of first $P$. aeruginosa infection, and \% predicted lung function. Cross-sectional comparisons between vitamin D groups were performed at ages 8,12 , and 16 years.

Measurements and Main Results: The prevalence of vitamin D deficiency and insufficiency increased slowly through adolescence. The rate of exacerbations for the deficient vitamin D group, aged 15 to 18 years, was 13.1 per 10 patient-years, significantly higher than 4.3 per 10 patient-years for the insufficient and sufficient vitamin $\mathrm{D}$ groups $(P<0.05)$, which were not significantly different There were no differences between vitamin $\mathrm{D}$ groups in pulmonary function or incidence of first $P$. aeruginosa infection, which was about 2 per 10 patient-years.

Conclusions: Higher 25-OHD levels in children with CF were associated with lower rates of pulmonary exacerbations and, in adolescents, higher $\mathrm{FEV}_{1}$.

Keywords: lung diseases; pediatrics; vitamin D

(Received in original form August 31, 2012; accepted in final form August 21, 2013)

Supported by the Cystic Fibrosis Foundation, 2nd and 3rd Year Clinical Research Fellowship Award MCCAUL09BO (L.A.M.); National Institutes of Health grants NIAMS K23 AR057789 (L.E.P.), K12 K12 HD068322 (T.A.L.), and UM CTSI UL1TR000114 (T.A.L.); and a Center Grant from the Cystic Fibrosis Foundation (W.E.R.).

Author Contributions: L.A.M.: conception and design of study, data interpretation, manuscript preparation. W.T.: design of study, data analysis and interpretation, manuscript revisions. T.A.L.: design of study, data interpretation, manuscript revisions. W.E.R.: design of study, data interpretation, manuscript revisions. A.M.: design of study, data interpretation, manuscript revisions. L.E.P.: design of study, data interpretation, manuscript revisions.

Correspondence and requests for reprints should be addressed to Laura A. McCauley, M.D., 1000 North Oak Street, Marshfield, WI 54449. E-mail: mccauley.laura@marshfieldclinic.org

Ann Am Thorac Soc Vol 11, No 2, pp 198-204, Feb 2014

Copyright (0) 2014 by the American Thoracic Society

DOI: 10.1513/AnnalsATS.201208-068OC

Internet address: www.atsjournals.org

Recent studies suggest that vitamin D has a role in lung growth, preserving lung function, and preventing pulmonary infection (1-7). The largest study comes from the Third National Health and Nutrition Examination Survey (NHANES III) data, which showed in healthy adults those with the highest 25-hydroxyvitamin
D (25-OHD) levels had significantly higher $\mathrm{FVC}$ and $\mathrm{FEV}_{1}$ than those with the lowest 25-OHD levels (3). In healthy infants and children, vitamin $\mathrm{D}$ deficiency has been associated with a higher risk of and more severe respiratory infections $(4,6-8)$.

Vitamin D deficiency is common in the cystic fibrosis (CF) population and ranges from 40 to $90 \%$, depending on age and definition of deficiency (9-14). The cause of vitamin $\mathrm{D}$ deficiency in CF is multifactorial, including pancreatic insufficiency, reduced sunlight exposure, poor body fat stores, and decreased vitamin $\mathrm{D}$-binding protein $(14,15)$. Increased risk of vitamin $\mathrm{D}$ deficiency 
may be intrinsic to the CF transmembrane conductance regulator mutation, as those with CF given high doses of ergocalciferol with pancreatic enzymes have less absorption and impaired conversion to 25-OHD than control subjects (16).

Vitamin D is an important factor to consider in the $\mathrm{CF}$ population, where pulmonary function and pulmonary exacerbations are major determinants of morbidity and mortality (17-20). In fact, one study showed that almost $25 \%$ of children failed to recover to baseline $\mathrm{FEV}_{1}$ after hospital admission for a pulmonary exacerbation (21). Studies on vitamin D and lung function in the CF population are lacking. Most studies focus on prevalence of vitamin D deficiency, supplementation, and bone health but comment on lung function as a possible predictor of vitamin $\mathrm{D}$ deficiency (22-24). These studies have had conflicting results, with only one study reporting a significant positive relationship between 25-OHD level and pulmonary function (23). Animal studies have suggested that vitamin $\mathrm{D}$ deficiency may affect lung function by limiting lung growth $(1,2)$. In vitro studies on $\mathrm{CF}$ bronchial epithelial cells have shown that vitamin D up-regulates cathelicidin, an antimicrobial with activity against Pseudomonas aeruginosa (25).

$P$. aeruginosa infection and colonization are important in $\mathrm{CF}$, as they can significantly decrease lung function and increase morbidity and mortality in this population $(18,26,27)$.

The relationship between vitamin $\mathrm{D}$ and lung function is still unclear, particularly in the CF population. It is unknown whether vitamin $\mathrm{D}$ has a linear dose response or a threshold effect on FVC and $\mathrm{FEV}_{1}$ as suggested by the NHANES data (3). It is also unknown if vitamin $\mathrm{D}$ deficiency is related to other markers of CF lung disease, such as pulmonary exacerbations and age of first detection of $P$. aeruginosa in sputum or oropharyngeal culture. Our study aimed to define the relationship between vitamin $\mathrm{D}$, lung function, and pulmonary exacerbations in children with CF and to determine if there is a threshold level of 25-OHD that optimizes its pulmonary effects. We hypothesized that children with $\mathrm{CF}$ and 25-OHD levels less than $20 \mu \mathrm{g} / \mathrm{L}$ and less than $30 \mu \mathrm{g} / \mathrm{L}$ would have lower pulmonary function and more frequent pulmonary exacerbations than those with
25-OHD levels greater than or equal to $30 \mu \mathrm{g} / \mathrm{L}$

\section{Methods}

\section{Study Subjects}

This retrospective longitudinal study analyzed pulmonary function tests (PFT) and 25-OHD in 130 children aged 6 to 18 years between 2000 and 2012, from the University of Minnesota Cystic Fibrosis Center's database. Patients were included if they were (1) diagnosed with CF by positive sweat test, defined as a chloride level greater than $60 \mathrm{mmol} / \mathrm{L}$ using pilocarpine iontophoresis, (2) had two known CF gene mutations on different chromosomes, and (3) had at least one 25-OHD measurement and one PFT measurement in the study period. Patients were excluded if they (1) were pancreatic sufficient (17 patients), as they do not have impaired absorption of vitamin $\mathrm{D}$ and other fat-soluble vitamins; and (2) had a history of liver transplant (two patients) or lung transplant (eight patients). PFT measurements were excluded from analysis after a patient had evidence of liver dysfunction, because this could affect vitamin $\mathrm{D}$ metabolism. Liver dysfunction was defined as an elevated alanine aminotransferase (ALT) or elevated aspartate aminotransferase (AST) three times the upper limit of normal (35 IU/L for girls and $40 \mathrm{IU} / \mathrm{L}$ for boys). The study period record for each patient began with their first measurement of 25-OHD between the ages of 6 and 18 years. All subsequent PFTs, measurements of body mass index (BMI) percentile, 25-OHD, and vitamins $A$ and $E$ were included through age 18 years or November 2012, or an elevated ALT or AST. Most patients contributed several years of data to the analysis. The University of Minnesota Institutional Review Board approved the study protocol, and participants had previously given informed consent as part of the database inclusion criteria, permitting their records to be used for research purposes.

\section{Measurements}

Pulmonary function testing was performed at outpatient visits using standardized spirometry. Lung function was measured by $\mathrm{FEV}_{1}, \mathrm{FVC}$, and $\mathrm{FEV}_{1} / \mathrm{FVC}$ from valid expiratory efforts per American Thoracic
Society Guidelines (28). All FVC and FEV measurements are reported as percent of predicted values, based on NHANES III norms (29). $\mathrm{FEV}_{1} / \mathrm{FVC}$ is reported as calculated from the original measurements. Only outpatient PFT results were used as lung function outcomes.

Pulmonary exacerbations were defined as hospitalizations, identified from the longitudinal record by inpatient PFTs. Our database manager verified that PFTs labeled as "inpatient" were consistent with the medical record for hospital admission. Dates for inpatient PFTs were used to define exacerbations as follows: A patient's first inpatient PFT during the study period was considered their first exacerbation, and all subsequent inpatient PFTs within 30 days were assumed to be part of the same hospital-treated exacerbation, because most patients are treated with antibiotics for a 21-day course. The next inpatient PFT more than 30 days later was considered the start of their second exacerbation, and the same 30-day window was applied. This count was performed throughout the patient record during the study period to identify all exacerbations. Inpatient PFTs were used only to identify exacerbations and not included as outcomes in any analysis.

Serum total 25-OHD concentrations were measured as part of CF annual studies, starting at 1 year of age. Measurements of total 25-OHD were performed using liquid chromatography/tandem mass spectrometry. Participants were divided into the following groups based on 25-OHD level: sufficient greater than or equal to $30 \mu \mathrm{g} / \mathrm{L}$, insufficient 20 to $29 \mu \mathrm{g} / \mathrm{L}$, and deficient less than $20 \mu \mathrm{g} / \mathrm{L}$. These definitions were based on published recommendations for defining vitamin $\mathrm{D}$ deficiency as 25-OHD less than $20 \mu \mathrm{g} / \mathrm{L}$ and the Cystic Fibrosis Foundation's recommendation for maintaining total 25-OHD levels between $30 \mu \mathrm{g} / \mathrm{L}$ and $60 \mu \mathrm{g} / \mathrm{L}(30-32)$. Vitamin A and vitamin E levels were measured by highperformance liquid chromatography.

Percentile of BMI was calculated using the SAS program from the Centers for Disease Control (http://www.cdc.gov/nccdphp/dnpao/ growthcharts/resources/sas.htm).

Pseudomonas aeruginosa was detected by routine surveillance sputum and/or oropharyngeal cultures performed quarterly at outpatient clinic visits using standard 
clinical microbiological protocols. The date of initial infection was the first detection of $P$. aeruginosa infection on sputum or oropharyngeal culture, recorded in the University of Minnesota Cystic Fibrosis Center's database.

\section{Statistical Methods}

In the longitudinal analyses of PFT, exacerbations, and $P$. aeruginosa outcomes, a child's vitamin D group often changed over time. For each child, the longitudinal record was formed by assigning all outcome measurements during each interval between 25-OHD measurements to the vitamin $\mathrm{D}$ group of the 25-OHD measurement that started the interval. That is, vitamin $\mathrm{D}$ group was carried forward from one 25-OHD measurement to the next 25-OHD measurement. All outcome measurements after an elevated AST-ALT were omitted.

Rates of exacerbation and of first $P$. aeruginosa infection were estimated and compared between groups using Poisson regression for repeated measurements, fit by generalized estimating equations. The model for $P$. aeruginosa infection contained only vitamin $\mathrm{D}$ group; the model for exacerbation contained vitamin D group, age group, and their interaction. PFT outcomes were compared using longitudinal regression models, with polynomials in age and a random intercept for each subject to model the mean path for each vitamin $\mathrm{D}$ group and a random intercept for each subject to model the correlation between measurements from the same child

We also report cross-sectional comparisons of vitamin $\mathrm{D}$ groups at ages 8,12 , and 16 years, with a single observation from each child. These three ages were chosen to survey the age range and so that each group had at least one child. In the cross-sectional analysis, sex proportions were compared by chi-square, and continuous variables were compared by analysis of variance for categorical vitamin $\mathrm{D}$ and linear regression for continuous vitamin D. Finally, simple linear regression was used to model \% predicted lung function as response on 25-OHD as a continuous predictor. Analyses were performed in SAS Version 9.3 (SAS Institute 2010, Cary, NC). Figures 1 and 2 were drawn in R (R Foundation for Statistical Computing, 2012, Vienna, Austria. http://www.R-project.org).
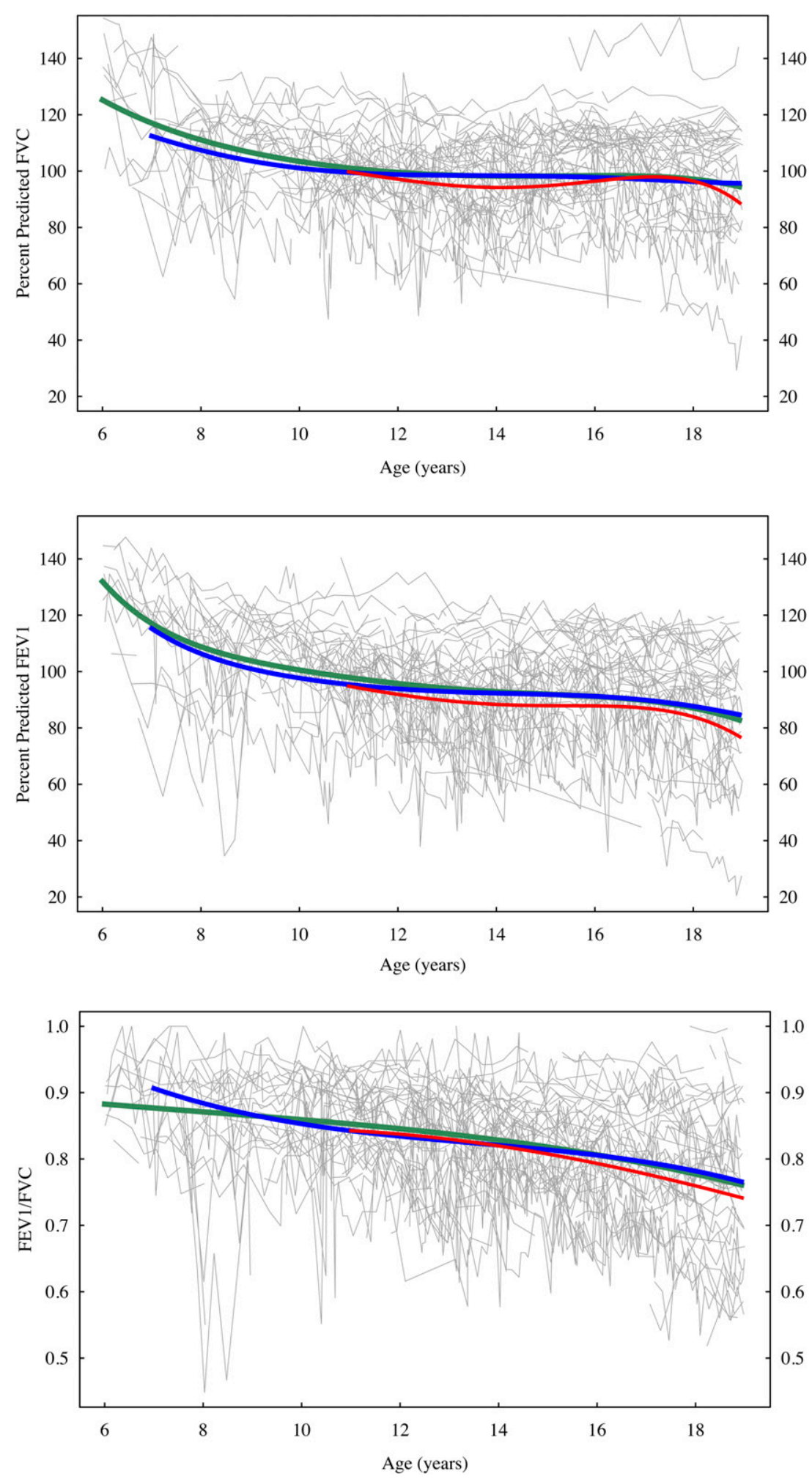

Figure 1. Percent predicted FVC, $\mathrm{FEV}_{1}$, and the ratio $\mathrm{FEV}_{1} / \mathrm{FVC}$, age 6 to 18 years. Light gray line segments show measurements for each child in the study. Green curve (age 6-18 yr) is fitted mean for sufficient vitamin D group; blue curve (age 7-18 yr) is fitted mean for insufficient vitamin D group; red curve (age 11-18 yr) is fitted mean for deficient vitamin D group. Fitted means are shown only for years in which a group contained at least four children. 


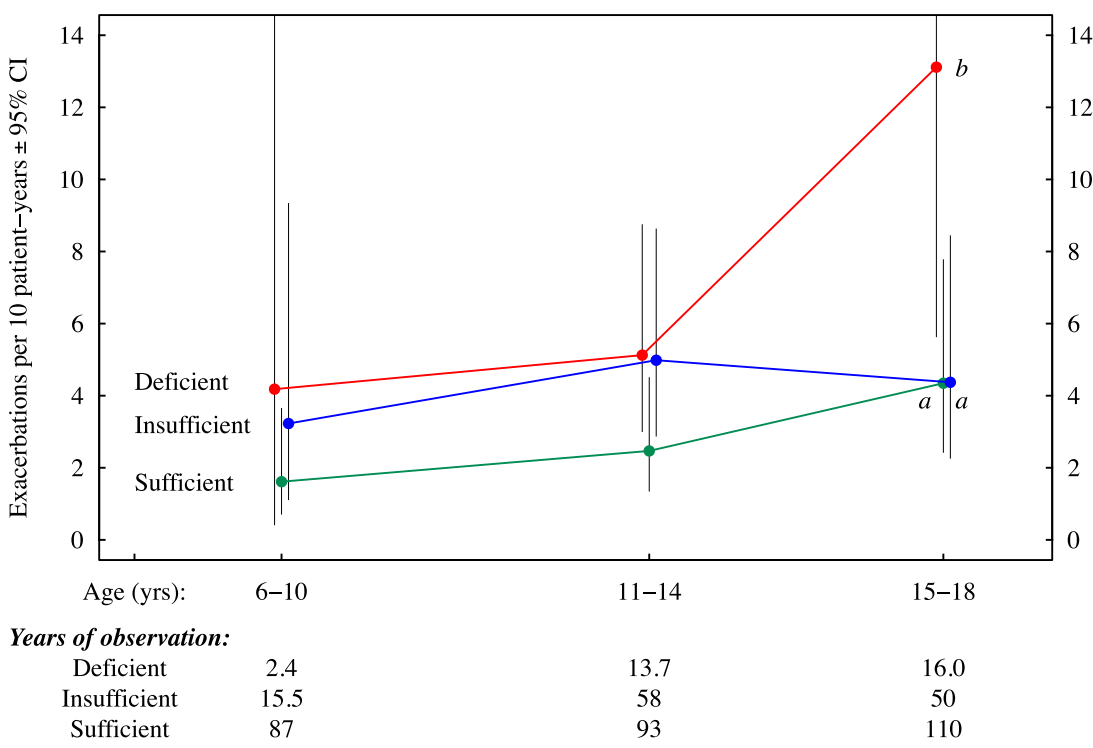

Figure 2. Numbers of hospitalizations for exacerbation per 10 patient-years, by vitamin $\mathrm{D}$ group and age category. Green line connects rates for sufficient vitamin D group; blue line connects rates for insufficient vitamin D group; red line connects rates for deficient vitamin D group. The rate of exacerbations for the deficient vitamin D group, ages 15 to 18 years (marked $b$ ), was significantly higher than for the insufficient and sufficient vitamin $D$ groups (marked $a, P<0.05$ ).

\section{Results}

There were 130 children aged 6 to 18 years between 2000 and November 2012 who met inclusion criteria, with a total of 2,247 PFTs and 468 measurements of 25-OHD. Initial 25-OHD levels for the 130 children were distributed roughly equally across ages 6 to 18 years, with median longitudinal record of 4 years. The proportions of children with insufficient or deficient 25-OHD increased slowly through adolescence: among children age 6 to 10 years, less than $5 \%$ were deficient and 10 to $20 \%$ were insufficient; among children 15 to 18 years, about $10 \%$ were deficient and $30 \%$ were insufficient (Table 1).

\section{Cross-sectional Comparison of Vitamin D Groups at Ages 8, 12, and 16 Years}

There were 28, 47, and 51 children with PFT measurements during their 8th, 12th, and 16 th year, respectively. Comparison of the vitamin $\mathrm{D}$ groups at each age for PFT and nutritional outcomes are shown in Table 1. There were no differences at any of the ages in sex proportion, PFT outcomes, or BMI percentile. Vitamins A and $\mathrm{E}$ were significantly lower in the deficient vitamin $\mathrm{D}$ group than in the sufficient vitamin $\mathrm{D}$ for 16-year-olds, and this also held for vitamin $\mathrm{E}$ in 12-year-olds.

As part of the cross-sectional comparison, linear regression of $\%$ predicted $\mathrm{FEV}_{1}$ on $25-\mathrm{OHD}$, without adjustment, found that in 16-year-olds, a $10-\mu \mathrm{g} / \mathrm{L}$ increase in 25-OHD was associated with an increase in predicted $\mathrm{FEV}_{1}$ of $5.5 \%$ (95\% confidence interval [CI], 0.5-10.5\%; $P=0.036)$, but the association was not statistically significant in the 8- and 12-year-olds.

\section{Longitudinal Comparison of Lung Function among Vitamin D Groups} Longitudinal comparison of vitamin D groups is shown in Figure 1, which illustrates the highly variable PFT responses of individuals over even short periods of time. There were no significant differences in mean $\mathrm{FEV}_{1}$, $\mathrm{FVC}$, or $\mathrm{FEV}_{1} / \mathrm{FVC}$ ratio between vitamin $\mathrm{D}$ groups, and the differences between estimated mean curves were much smaller than the decline in PFT with age.

\section{Pulmonary Exacerbations and First Detection of $P$. aeruginosa Infection Rates}

Numbers of patients hospitalized with pulmonary exacerbations per 10 patient-years, by vitamin D group and age category, are shown in Figure 2. The rate of exacerbations for the deficient vitamin D group, aged 15 to 18 years, was 13 per 10 patient-years (95\% CI, 6-31), significantly higher than 4.3 per 10 patient-years (95\% CI, 2-8) for the insufficient and sufficient vitamin $\mathrm{D}$ groups $(P=0.041$ and $P=0.035$, respectively).

Most of the children had their first $P$. aeruginosa infection before the beginning of their record during the study period, leaving only 48 (37\%) who were at risk during the study period. For these 48, the incidence of $P$. aeruginosa infection was about 2 per 10 patient-years, with no difference between vitamin $\mathrm{D}$ groups.

\section{Discussion}

We expected a relationship between vitamin $\mathrm{D}$ deficiency and lung function but were surprised to find a stronger association between vitamin D deficiency and number of pulmonary exacerbations. We found that in children aged 15 to 18 years with $\mathrm{CF}$, those with total $25-\mathrm{OHD}$ levels greater than or equal to $20 \mu \mathrm{g} / \mathrm{L}$ have significantly fewer pulmonary exacerbations than those with total 25-OHD levels less than $20 \mu \mathrm{g} / \mathrm{L}$. This is important in the management of CF, wherein pulmonary exacerbations have been shown at various ages to negatively impact lung function, increase mortality, and decrease quality of life $(18,20,21)$. We did not see a significant difference in pulmonary exacerbations between those with vitamin $\mathrm{D}$ levels greater than or equal to $30 \mu \mathrm{g} / \mathrm{L}$ and those with vitamin D levels 20 to $29 \mu \mathrm{g} / \mathrm{L}$, as originally hypothesized. We also noted only a significant linear relationship between vitamin $\mathrm{D}$ and $\mathrm{FEV}_{1}$ over time in adolescents as well. This suggests that vitamin $\mathrm{D}$ deficiency may have a cumulative effect over time.

The mechanism by which vitamin D may prevent pulmonary exacerbations could be related to protection from viral infection. Viral infections, including respiratory syncytial virus, influenza $A$, influenza $B$, and rhinovirus, are a significant cause of pulmonary exacerbations in children with $\mathrm{CF}$, accounting for up to $60 \%$ of exacerbations (33-35). Multiple 
Table 1. Cross-sectional comparison of vitamin D categories in children aged 8, 12, and 16 years

\begin{tabular}{|c|c|c|c|c|c|}
\hline & Age (yr) & Deficient $(\leq 20 \mu \mathrm{g} / \mathrm{L})$ & Insufficient (20-29 $\mu \mathrm{g} / \mathrm{L})$ & Sufficient $(\geq 30 \mu \mathrm{g} / \mathrm{L})$ & $P$ Value \\
\hline \multirow[t]{2}{*}{ No. (\% age total) } & 8 & $1(4)$ & $3(11)$ & $24(86)$ & \\
\hline & 12 & $5(11)$ & $15(32)$ & $27(57)$ & \\
\hline \multirow[t]{3}{*}{ 25-OHD, $\mu \mathrm{g} / \mathrm{L}$} & 8 & 17 & $21 \pm 1$ & $39 \pm 6$ & \\
\hline & 12 & $16 \pm 3$ & $26 \pm 3$ & $36 \pm 7$ & \\
\hline & 16 & $15 \pm 4$ & $25 \pm 3$ & $38 \pm 6$ & \\
\hline \multirow[t]{3}{*}{$\mathrm{FEV}_{1} \%$ predicted } & 8 & 104 & $91 \pm 27$ & $107 \pm 18$ & 0.410 \\
\hline & 12 & $88 \pm 17$ & $89 \pm 19$ & $95 \pm 15$ & 0.418 \\
\hline & 16 & $87 \pm 15$ & $88 \pm 18$ & $100 \pm 18$ & 0.072 \\
\hline \multirow[t]{3}{*}{ FVC\% predicted } & 8 & 96 & $110 \pm 6$ & $109 \pm 14$ & 0.647 \\
\hline & 12 & $94 \pm 13$ & $95 \pm 17$ & $98 \pm 14$ & 0.750 \\
\hline & 16 & $98 \pm 13$ & $96 \pm 20$ & $106 \pm 15$ & 0.145 \\
\hline & 16 & $47 \pm 34$ & $49 \pm 30$ & $51 \pm 21$ & 0.910 \\
\hline \multirow{3}{*}{ Vitamin $A, m g / L$} & 8 & 0.48 & $0.36 \pm 0.05$ & $0.46 \pm 0.11$ & 0.407 \\
\hline & 12 & $0.43 \pm 0.10$ & $0.43 \pm 0.05$ & $0.48 \pm 0.15$ & 0.480 \\
\hline & 16 & $0.44 \pm 0.09 a$ & $0.54 \pm 0.17 a$ & $0.62 \pm 0.18 b$ & 0.092 \\
\hline \multirow[t]{3}{*}{ Vitamin E, mg/L } & 8 & 8.1 & $8.9 \pm 2$ & $12.1 \pm 4$ & 0.290 \\
\hline & 12 & $6.6 \pm 1 a$ & $9.0 \pm 4 b$ & $11.4 \pm 4 b$ & 0.016 \\
\hline & 16 & $6.3 \pm 2 a$ & $9.5 \pm 3 a$ & $10.7 \pm 3 b$ & 0.030 \\
\hline
\end{tabular}

Definition of abbreviation: $25-\mathrm{OHD}=25$-hydroxy vitamin $\mathrm{D}$; $\mathrm{BMI}=$ body mass index.

Values are mean $\pm \mathrm{SD}$ or $\mathrm{n}(\%)$. $P$ values are from overall comparison. For each outcome within each age, Vitamin $\mathrm{D}$ groups were compared by pairwise linear contrasts. Means or percents with no letters in common (a or $b)$ were significantly different $(P<0.05)$.

studies have demonstrated a link between vitamin $\mathrm{D}$ deficiency and an increased risk of viral illness (4-7). Data from NHANES III showed that in those aged 12 years and older, 25-OHD levels were inversely related to the risk of recent upper respiratory tract infection (4). In addition, those with 25-OHD levels less than $10 \mu \mathrm{g} / \mathrm{L}$ had a 55\% higher likelihood of developing an upper respiratory tract infection than those with serum levels greater than or equal to $30 \mu \mathrm{g} / \mathrm{L}$ (4). A randomized, placebo-controlled trial in school children found a lower incidence of influenza $\mathrm{A}$ in children treated with vitamin $\mathrm{D}$ compared with those treated with placebo during the influenza season (5). In infants, it has been shown that low vitamin $\mathrm{D}$ in cord blood samples at birth is associated with higher incidence of respiratory syncytial virus (6), and infants readmitted to the neonatal intensive care unit with acute lower respiratory tract infection had lower vitamin D levels than age-matched control subjects (7). In adults with $\mathrm{CF}$, those who received a high dose of cholecalciferol (250,000 IU) once at the time of admission for a pulmonary exacerbation had significantly fewer hospitalizations for pulmonary exacerbations over the next 6 months compared with those receiving placebo (36). Combined, these studies suggest that vitamin $\mathrm{D}$ may prevent viral infection and possibly work as an adjunct treatment to antibiotics to decrease the severity of an exacerbation.

To our knowledge, this is the first retrospective study describing the longitudinal relationship between vitamin $\mathrm{D}$ and lung function as well as other markers of pulmonary disease such as pulmonary exacerbations and pseudomonas acquisition in children with CF. Other studies have examined the prevalence of vitamin D deficiency in $\mathrm{CF}$ and examined its association with $\mathrm{FEV}_{1}$ cross-sectionally. Similar to our results, most of these studies have found no association between vitamin $\mathrm{D}$ deficiency and $\mathrm{FEV}_{1}(10,12,23,37)$. We did, however, see a linear relationship between vitamin $\mathrm{D}$ level and $\mathrm{FEV}_{1}$ in the adolescent age group. The former studies may not have seen a linear relationship, as they did not adjust for age, and two had a mean age of 9 and 11 years, younger than the adolescent population with significant findings in our study $(12,37)$. In the third study, $81 \%$ of patients were vitamin $\mathrm{D}$ deficient or insufficient and may not have had enough patients with 25-OHD levels greater than $30 \mu \mathrm{g} / \mathrm{L}$ to see a significant trend. Similar to our findings in adolescents, one study reported a significant positive linear relationship between vitamin $\mathrm{D}$ and $\mathrm{FEV}_{1}$ (23). Although we did not find a statistically significant difference in lung function using defined thresholds in the younger age groups, $\mathrm{FEV}_{1}$ ranged from 3 to $13 \%$ higher in the sufficient group compared with the deficient group. Although this is not statistically significant, its potential clinical relevance should not be overlooked, particularly in a population whose $\mathrm{FEV}_{1}$ declines, on average, by 1 to $3 \%$ per year (38).

It is unclear why the prevalence of vitamin D deficiency increases with age. This has been found in both 
healthy adolescent-aged children and adolescents with CF $(10,12,39)$. One would speculate change in dietary habits, such as decreased milk and increased soda consumption. Poor compliance with medications is seen in adolescents, although in our patients vitamin A and $\mathrm{E}$ were within normal limits, suggesting compliance with vitamin supplementation. BMI was also normal, suggesting proper nutrition and less severe disease (40).

\section{Study Limitations}

This was a retrospective study of patients from a single clinical center. One of our primary outcomes, exacerbation, has no consensus definition. We were limited to counting exacerbations requiring hospitalization, not exacerbations treated at home, and thus underestimated actual rates of exacerbation. Our small sample size prevented adjustment for BMI percentile, 25-OHD supplementation, seasonal differences in 25-OHD, sex, microbiology, other therapies, or other confounders, although BMI, the most important confounder, was similar in all three vitamin D groups. The sample size for first $P$. aeruginosa infection was less than one-half our study sample, because most children in the study had experienced their first $P$. aeruginosa infection before the beginning of the study period at age 6 . Our results are not generalizable to patients with CF with sufficient pancreatic function, because we excluded these patients from our analyses. Last, we did not have information on the treatment of vitamin $\mathrm{D}$ deficiency, which may be viewed as a confounder in that those receiving treatment may be followed more closely in clinic. In our clinic, though, those on treatment usually are reevaluated during their routine quarterly visits to determine changes in vitamin $\mathrm{D}$ supplementation. However, the strengths of this study are the longitudinal assessment and that it is the first study we know of designed specifically to describe the relationship between vitamin $\mathrm{D}$ deficiency and other markers of CF-related pulmonary disease, such as pulmonary exacerbations and
$P$. aeruginosa infection in children with CF.

In conclusion, our study showed that 25-OHD level less than or equal to $20 \mu \mathrm{g} / \mathrm{L}$ in children with CF is associated with a three times higher rate of pulmonary exacerbations than those sufficient in vitamin $\mathrm{D}$. In addition, in adolescents with CF, a higher vitamin D level was associated with higher $\mathrm{FEV}_{1}$. Therefore, it is possible that treatment with vitamin $\mathrm{D}$ may preserve lung function and improve quality of life in children with CF. Controlled clinical trials are needed to determine the impact of vitamin $\mathrm{D}$ on lung function and its role in preventing pulmonary exacerbations in individuals with CF. Multicenter studies with a larger sample size are needed to confirm these findings.

Author disclosures are available with the text of this article at www.atsjournals.org.

Acknowledgment: The authors thank our database managers, Bonnie Holme and Catherine Moen, as well as all study participants and their parents.

\section{References}

1 Gaultier C, Harf A, Balmain N, Cuisinier-Gleizes P, Mathieu H. Lung mechanics in rachitic rats. Am Rev Respir Dis 1984;130:1108-1110.

2 Zosky GR, Berry LJ, Elliot JG, James AL, Gorman S, Hart PH. Vitamin $D$ deficiency causes deficits in lung function and alters lung structure. Am J Respir Crit Care Med 2011;183:1336-1343.

3 Black PN, Scragg R. Relationship between serum 25-hydroxyvitamin $\mathrm{D}$ and pulmonary function in the third national health and nutrition examination survey. Chest 2005;128:3792-3798.

4 Ginde AA, Mansbach JM, Camargo CA Jr. Association between serum 25-hydroxyvitamin $D$ level and upper respiratory tract infection in the Third National Health and Nutrition Examination Survey. Arch Intern Med 2009;169:384-390.

5 Urashima M, Segawa T, Okazaki M, Kurihara M, Wada Y, Ida H. Randomized trial of vitamin $D$ supplementation to prevent seasonal influenza A in schoolchildren. Am J Clin Nutr 2010;91: 1255-1260.

6 Belderbos ME, Houben ML, Wilbrink B, Lentjes E, Bloemen EM, Kimpen JL, Rovers M, Bont L. Cord blood vitamin D deficiency is associated with respiratory syncytial virus bronchiolitis. Pediatrics 2011;127:e1513-e1520.

7 Karatekin G, Kaya A, Salihoğlu O, Balci H, Nuhoğlu A. Association of subclinical vitamin $D$ deficiency in newborns with acute lower respiratory infection and their mothers. Eur J Clin Nutr 2009;63: 473-477.

8 McNally JD, Leis K, Matheson LA, Karuananyake C, Sankaran K, Rosenberg AM. Vitamin D deficiency in young children with severe acute lower respiratory infection. Pediatr Pulmonol 2009;44:981-988.

9 Neville LA, Ranganathan SC. Vitamin D in infants with cystic fibrosis diagnosed by newborn screening. J Paediatr Child Health 2009;45:36-41.

10 Rovner AJ, Stallings VA, Schall JI, Leonard MB, Zemel BS. Vitamin D insufficiency in children, adolescents, and young adults with cystic fibrosis despite routine oral supplementation. Am J Clin Nutr 2007;86:1694-1699.
11 Grey V, Atkinson S, Drury D, Casey L, Ferland G, Gundberg C, Lands LC. Prevalence of low bone mass and deficiencies of vitamins $D$ and $\mathrm{K}$ in pediatric patients with cystic fibrosis from 3 Canadian centers. Pediatrics 2008;122:1014-1020.

12 Chavasse RJ, Francis J, Balfour-Lynn I, Rosenthal M, Bush A. Serum vitamin $\mathrm{D}$ levels in children with cystic fibrosis. Pediatr Pulmonol 2004;38:119-122.

13 Elkin SL, Fairney A, Burnett S, Kemp M, Kyd P, Burgess J, Compston JE, Hodson ME. Vertebral deformities and low bone mineral density in adults with cystic fibrosis: a cross-sectional study. Osteoporos Int 2001;12:366-372.

14 Hall WB, Sparks AA, Aris RM. Vitamin D deficiency in cystic fibrosis. Int J Endocrinol 2010;2010:218691.

15 Coppenhaver D, Kueppers F, Schidlow D, Bee D, Isenburg JN, Barnett $\mathrm{DR}$, Bowman BH. Serum concentrations of vitamin D-binding protein (group-specific component) in cystic fibrosis. Hum Genet 1981;57:399-403.

16 Lark RK, Lester GE, Ontjes DA, Blackwood AD, Hollis BW, Hensler MM, Aris RM. Diminished and erratic absorption of ergocalciferol in adult cystic fibrosis patients. Am J Clin Nutr 2001;73:602-606.

17 Kerem E, Reisman J, Corey M, Canny GJ, Levison H. Prediction of mortality in patients with cystic fibrosis. N Engl J Med 1992;326: 1187-1191.

18 Emerson J, Rosenfeld M, McNamara S, Ramsey B, Gibson RL. Pseudomonas aeruginosa and other predictors of mortality and morbidity in young children with cystic fibrosis. Pediatr Pulmonol 2002;34:91-100.

19 de Boer K, Vandemheen KL, Tullis E, Doucette S, Fergusson D, Freitag A, Paterson N, Jackson M, Lougheed MD, Kumar V, et al. Exacerbation frequency and clinical outcomes in adult patients with cystic fibrosis. Thorax 2011;66:680-685.

20 Britto MT, Kotagal UR, Hornung RW, Atherton HD, Tsevat J, Wilmott RW. Impact of recent pulmonary exacerbations on quality of life in patients with cystic fibrosis. Chest 2002;121:64-72. 
21 Sanders DB, Hoffman LR, Emerson J, Gibson RL, Rosenfeld M, Redding GJ, Goss $\mathrm{CH}$. Return of FEV1 after pulmonary exacerbation in children with cystic fibrosis. Pediatr Pulmonol 2010;45:127-134.

22 Stephenson A, Brotherwood M, Robert R, Atenafu E, Corey M, Tullis E. Cholecalciferol significantly increases 25 -hydroxyvitamin D concentrations in adults with cystic fibrosis. Am J Clin Nutr 2007;85:1307-1311.

23 Green D, Carson K, Leonard A, Davis JE, Rosenstein B, Zeitlin P, Mogayzel P Jr. Current treatment recommendations for correcting vitamin $\mathrm{D}$ deficiency in pediatric patients with cystic fibrosis are inadequate. J Pediatr 2008;153:554-559.

24 Wolfenden LL, Judd SE, Shah R, Sanyal R, Ziegler TR, Tangpricha V. Vitamin $D$ and bone health in adults with cystic fibrosis. Clin Endocrinol (Oxf) 2008;69:374-381.

25 Yim S, Dhawan P, Ragunath C, Christakos S, Diamond G. Induction of cathelicidin in normal and CF bronchial epithelial cells by 1,25-dihydroxyvitamin D(3). J Cyst Fibros 2007;6:403-410.

26 Que C, Cullinan P, Geddes D. Improving rate of decline of FEV1 in young adults with cystic fibrosis. Thorax 2006;61:155-157.

27 Ren CL, Rosenfeld M, Mayer OH, Davis SD, Kloster M, Castile RG, Hiatt PW, Hart M, Johnson R, Jones P, et al. Analysis of the associations between lung function and clinical features in preschool children with cystic fibrosis. Pediatr Pulmonol 2012;47(6):574-581.

28 Miller MR, Hankinson J, Brusasco V, Burgos F, Casaburi R, Coates A, Crapo R, Enright P, van der Grinten CP, Gustafsson P, et al.; ATS/ERS Task Force. Standardisation of spirometry. Eur Respir J 2005;26:319-338.

29 Hankinson JL, Odencrantz JR, Fedan KB. Spirometric reference values from a sample of the general U.S. population. Am J Respir Crit Care Med 1999;159:179-187.

30 Tangpricha V, Kelly A, Stephenson A, Maguiness K, Enders J, Robinson KA, Marshall BC, Borowitz D; Cystic Fibrosis Foundation Vitamin D Evidence-Based Review Committee. An update on the screening, diagnosis, management, and treatment of vitamin $D$ deficiency in individuals with cystic fibrosis: evidence-based recommendations from the Cystic Fibrosis Foundation. J Clin Endocrinol Metab 2012;97:1082-1093.
31 Misra M, Pacaud D, Petryk A, Collett-Solberg PF, Kappy M; Drug and Therapeutics Committee of the Lawson Wilkins Pediatric Endocrine Society. Vitamin D deficiency in children and its management: review of current knowledge and recommendations. Pediatrics 2008;122:398-417.

32 Ross AC, Manson JE, Abrams SA, Aloia JF, Brannon PM, Clinton SK, Durazo-Arvizu RA, Gallagher JC, Gallo RL, Jones G, et al. The 2011 report on dietary reference intakes for calcium and vitamin D from the Institute of Medicine: what clinicians need to know. $J$ Clin Endocrinol Metab 2011;96:53-58.

33 Asner S, Waters V, Solomon M, Yau Y, Richardson SE, Grasemann H, Gharabaghi $F$, Tran D. Role of respiratory viruses in pulmonary exacerbations in children with cystic fibrosis. J Cyst Fibros 2012;11: 433-439.

34 Wat D, Gelder C, Hibbitts S, Cafferty F, Bowler I, Pierrepoint M, Evans $\mathrm{R}$, Doull I. The role of respiratory viruses in cystic fibrosis. $J$ Cyst Fibros 2008;7:320-328.

35 Armstrong D, Grimwood K, Carlin JB, Carzino R, Hull J, Olinsky A, Phelan PD. Severe viral respiratory infections in infants with cystic fibrosis. Pediatr Pulmonol 1998;26:371-379.

36 Grossmann RE, Zughaier SM, Kumari M, Seydafkan S, Lyles RH, Liu S, Sueblinvong V, Schechter MS, Stecenko AA, Ziegler TR, et al. Pilot study of vitamin D supplementation in adults with cystic fibrosis pulmonary exacerbation: a randomized, controlled trial. Dermatoendocrinol 2012;4:191-197.

37 Henderson RC, Lester G. Vitamin D levels in children with cystic fibrosis. South Med J 1997;90:378-383.

38 Liou TG, Elkin EP, Pasta DJ, Jacobs JR, Konstan MW, Morgan WJ, Wagener JS. Year-to-year changes in lung function in individuals with cystic fibrosis. J Cyst Fibros 2010;9:250-256.

39 Robinson C, Chiang M, Thompson SN, Sondike SB. Occurrence of vitamin $D$ deficiency in pediatric patients at high risk in West Virginia. South Med J 2012;105(10):504-507.

40 Steinkamp G, Wiedemann B. Relationship between nutritional status and lung function in cystic fibrosis: cross sectional and longitudinal analyses from the German CF quality assurance (CFQA) project. Thorax 2002;57:596-601. 